\title{
AVALIAÇÃO DA CV. CABERNET FRANC PARA ELABORAÇÃO DE VINHO TINTO' ${ }^{1}$
}

\author{
Luiz Antenor RIZZON ${ }^{2, *}$, Alberto MIELE ${ }^{3}$
}

\begin{abstract}
RESUMO
A uva Cabernet Franc, originária da região de Bordeaux, França, foi introduzida no Rio Grande do Sul através da Estação Agronômica de Porto Alegre. É utilizada para a elaboração de vinho tinto para ser consumido jovem, embora apresente aptidão para envelhecer. Face a sua importância, conduziu-se este trabalho com o objetivo de determinar as características agronômicas e enológicas da uva Cabernet Franc para elaboração de vinho tinto. Para isso, realizaram-se estudos para caracterizar o cacho, o mosto e o vinho tinto nas safras de 1987 a 1994. Os resultados obtidos evidenciaram que a cv. Cabernet Franc tem cacho médio, formado por bagas pequenas. O mosto possui teores de açúcar e de acidez adequados para vinificação. $O$ vinho apresenta elevado teor de $\mathrm{K}$ e de álcoois superiores. No aspecto sensorial, apresenta cor vermelho-rubi, com reflexos violáceos quando jovem, e de intensidade variável em função das safras vitícolas. No olfato, apresenta aroma com notas vegetais e frutadas, que lembram pimentão e frutas vermelhas, respectivamente. Gustativamente, o vinho apresenta boa estrutura, equilíbrio e personalidade marcante.
\end{abstract}

Palavras-chave: enologia; uva; Cabernet Franc; caracterização.

\section{SUMMARY}

EVALUATION OF CV. CABERNET FRANC TO ELABORATE RED WINE. Cabernet Franc grape is originated from Bordeaux, France. It was introduced in the Serra Gaúcha region in the south of Brazil, by the Estação Agronômica the Porto Alegre, RS. It is used to elaborate young red wine, but it can be aged too. Due to the importance of Cabernet Franc, this work had the objective to determine its agronomic and winemaking characteristics. To achieve this purpose, variables related to the berries, clusters, must, and wine were performed from 1987 to 1994 . The results showed that Cabernet Franc grapes have clusters of medium size and small berries. The must has adequate sugar and titratable acidity levels for vinification. The Cabernet Franc wine has a high concentration of $\mathrm{K}$ and higher alcohols. The sensory evaluation showed that it has a ruby color with violet reflexes when young and presents color intensity varying with the vintage. The aroma is characterized by red fruits and pimiento. In the mouth it has good structure and equilibrium and a nice personality.

Keywords: enology; grape; Vitis vinifera; Cabernet Franc wine; characterization.

\section{1 - INTRODUÇÃO}

A uva Cabernet Franc, originária da região de Bordeaux, França, foi introduzida no Rio Grande do Sul através da Estação Agronômica de Porto Alegre na pri-

\footnotetext{
${ }_{1}^{1}$ Recebido para publicação em 27/06/01. Aceito para publicação em 06/08/01.

${ }^{2}$ Eng. Agr., Dr., EMBRAPA Uva e Vinho, Caixa Postal 130, CEP 95700-000 Bento Gonçalves-RS. E-mail: rizzon@cnpuv.embrapa.br ${ }^{3}$ Eng.-Agr., Dr., EMBRAPA Uva e Vinho.

${ }^{*}$ A quem a correspondência deve ser enviada.
}

meira metade do século $\mathrm{XX}$, de onde foi difundida para os municípios da Serra Gaúcha. O maior incremento no plantio dessa cultivar foi observado a partir de 1970. A safra de 1985, com a produção de 10,3 milhões de quilos, foi a que apresentou maior volume de produção [11]. Mas nas últimas safras vitícolas observou-se um decréscimo de produção [6], provavelmente em decorrência de problemas fitossanitários, especialmente de viroses [12, 27]. Segundo dados da Divisão de Enologia da Secretaria da Agricultura e Abastecimento do Rio Grande do Sul, a produção de Cabernet Franc em 2001 foi de 2,99 milhões de quilos.

Bento Gonçalves é, no momento, o município com maior área plantada de uva Cabernet Franc, seguido por Garibaldi, Monte Belo do Sul e Farroupilha, na Serra Gaúcha, e Santana do Livramento, na Campanha.

O destino da produção da uva Cabernet Franc é para a elaboração de vinho tinto jovem, embora apresente aptidão para envelhecer. Um pequeno volume de uva é utilizada também para a elaboração de vinho branco e para espumante.

Entre os trabalhos efetuados com a cv. Cabernet Franc na Serra Gaúcha, MOREIRA FILHO [16] descreveu as principais características físicas da uva e dos constituintes do mosto; BÁN [3] efetuou estudo ampelográfico da cultivar; MIELE et al [13], estudaram o efeito da calciocianamida na quebra de dormência, fertilidade das gemas, produtividade do vinhedo e qualidade da uva Cabernet Franc e MIELE et al [14, 15] avaliaram as características analíticas e sensoriais do vinho Cabernet Franc de diferentes regiões vitícolas da Serra Gaúcha. PASSOS [18] avaliou o efeito da intensidade de poda seca sobre a produtividade e o vigor da videira Cabernet Franc; ZANUZ et al [27], estudaram o efeito da virose do enrolamento da folha na composição química do vinho; e MANFROI [12] determinou as principais características biológicas e enológicas dessa cultivar conduzida no sistema de lira aberta.

Devido à importância socioeconômica da uva Cabernet Franc na Serra Gaúcha e a pouca disponibilidade de informações, realizou-se o presente trabalho para avaliar a sua aptidão para elaboração de vinho tinto. Nesse sentido, foram realizados estudos sobre a evolução da maturação e a caracterização da uva, do mosto e do vinho.

\section{2 - MATERIAL E MÉTODOS}

O trabalho foi realizado na EMBRAPA Uva e Vinho, Bento Gonçalves, RS, nas safras de 1987 a 1994. Utilizaram-se quinze plantas previamente marcadas de um vinhedo da cv. Cabernet Franc (Vitis vinifera L.), 
formado em 1981 e enxertado sobre o porta-enxerto SO4 (Vitis berlandieri x Vitis riparia - Seleção Oppenheim $\left.n^{\circ} 4\right)$. O vinhedo era conduzido em espaldeira e o espaçamento entre plantas era de $1,5 \mathrm{~m}$ e entre fileiras de $2,5 \mathrm{~m}$.

O acompanhamento da maturação da uva foi feito com 10 a 12 amostragens por ano, através da coleta de 300 bagas em cada amostragem. O trabalho iniciava no dia $22 / 12$ de cada ano e finalizava por ocasião da colheita da uva. As amostras eram levadas ao laboratório em saco plástico onde efetuava-se a pesagem de três grupos de 100 bagas para determinar a evolução do peso da baga. A seguir, eram esmagadas manualmente para extrair o mosto, o qual foi centrifugado. Analisaram-se as variáveis ${ }^{\circ}$ Brix, densidade, acidez titulável e $\mathrm{pH}$ por métodos físico-químicos [1].

As características da uva foram determinadas através de medidas efetuadas por ocasião da colheita da uva. O peso do cacho, o número de bagas por cacho, o peso da ráquis e a relação peso da ráquis/peso do cacho foram determinados através das medidas feitas em 15 cachos de uva colhidos ao acaso. O peso da semente e a relação peso da semente/peso da baga foram determinados retirando as sementes de 100 bagas.

As características analíticas do mosto, como densidade, 'Brix, acidez titulável, relação ${ }^{\circ}$ Brix/acidez titulável, $\mathrm{pH}$, ácido tartárico, ácido málico e relação ácido tartárico/ ácido málico foram obtidas do mosto extraído por ocasião do esmagamento da uva para microvinificação.

Os ácidos tartárico e málico foram analisados através da cromatografia líquida de alta eficiência (CLAE). Utilizou-se um cromatógrafo líquido Varian operando em condição isocrática, um detector espectrofotométrico UVIVIS, modelo UV-50 e um injetor Rheodyne $7125 \mathrm{com}$ volume de $20 \mu \mathrm{L}$. A separação do ácido tartárico foi realizada em uma coluna MCA-NCAP-5 de $15 \mathrm{~cm} \times 4,6 \mathrm{~mm}$ de diâmetro interno. O detetor foi fixado em um comprimento de onda de $212 \mathrm{~nm}$. Na eluição utilizou-se um solvente constituído de água ultrapura acidificada com ácido fosfórico a pH 2,5 [2].

As características da baga - peso, comprimento, largura e peso da semente - foram determinadas através da avaliação efetuada na baga por ocasião da coIheita da uva. O peso da baga foi determinado através da pesagem de três grupos de 100 bagas. A medida de seu comprimento e de sua largura foram efetuadas em 30 bagas, com um paquímetro.

Os vinhos foram elaborados em pequena escala, sendo realizadas três microvinificações de $18 \mathrm{~kg}$ de uva em cada safra. Inicialmente a baga foi separada da ráquis e, a seguir, esmagada com uma desengaçadeiraesmagadeira, momento em que retiraram-se amostras de mosto para análise. O mosto foi, então, colocado em recipientes de $20 \mathrm{~L}$, adaptados com uma válvula de Müller, nos quais adicionaram-se $\mathrm{SO}_{2}$ na concentração de $50 \mathrm{mg} \mathrm{L}^{-1}$ e leveduras secas ativas (Saccharomyces cerevisiae) na proporção de $0,20 \mathrm{~g} \mathrm{~L}^{-1}$. Não foi feita correção do açúcar do mosto. O tempo de maceração foi de cinco dias, com duas remontagens diárias. A fermentação alcoólica ocorreu em uma sala com temperatura entre $23^{\circ} \mathrm{C}$ e $25^{\circ} \mathrm{C}$. O vinho foi trasfegado, filtrado, engarrafado e depois analisado.

Inicialmente, foi feita a avaliação sensorial para descrever as principais características do vinho Cabernet Franc. Utilizou-se um copo com as dimensões definidas pela Associação Francesa de Normas Técnicas (AFNOR), descrevendo-se as principais características visuais, olfativas e sensoriais do vinho de cada safra. As determinações físico-químicas dos vinhos, tais como densidade, álcool, acidez titulável, acidez volátil, $\mathrm{pH}$, extrato seco, açúcares redutores, cinzas, alcalinidade das cinzas, nitrogênio total e dióxido de enxofre total foram feitas conforme metodologia descrita por RIBÉREAUGAYON et al [20]. As antocianinas foram determinadas pelo método de diferença de $\mathrm{pH}$ e os taninos através da hidrólise ácida [21, 22]; a densidade óptica, com comprimentos de onda de $420 \mathrm{~nm}$ e $520 \mathrm{~nm}$; e os polifenóis totais foram determinados com um espectrofotômetro UV/VIS, com cubetas de $1 \mathrm{~mm}$ e de $10 \mathrm{~mm}$ de percurso óptico, para os índices de cor e os polifenóis totais, respectivamente.

Os compostos voláteis aldeído acético, acetato de etila, metanol, 1-propanol, 2-metil-1-propanol, 2-metil1-butanol + 3-metil-1-butanol foram determinados por cromatografia gasosa. Utilizou-se um aparelho equipado com um detetor de ionização de chama e coluna de aço inoxidável Carbowax 600 a $5 \%$ mais Hallcomid M180L como fase estacionária e Chromosorb W de 6080 mesh como suporte, de $3,2 \mathrm{~m}$ de comprimento e de $1 / 8$ " de diâmetro interno. A amostra de vinho $(3 \mu L)$ foi injetada diretamente no aparelho após ter recebido $10 \%$ do volume de uma solução de 4-metil-2-pentanol a $1 \mathrm{~g} \mathrm{~L}^{-1}$ como padrão interno [4]. O teor de $\mathrm{P}$ foi determinado por colorimetria usando molibdato de amônio. $O$ $\mathrm{Ca}, \mathrm{Mg}, \mathrm{Mn}, \mathrm{Fe}$, Cu e $\mathrm{Zn}$ foram analisados por absorção atômica, enquanto que o K, Na, Li e Rb, por emissão de chama [19].

\section{3 - RESULTADOS E DISCUSSÃO}

\section{1 - Maturação da uva}

A evolução do peso da baga durante a maturação da uva Cabernet Franc é mostrada na Figura 1. Observou-se um incremento moderado no peso da baga no período de 22/12 até 19/01 e um incremento maior no período de 26/01 a 02/02, mas com maior desvio padrão, e continuando até a maturação da uva. O peso da baga da cv. Cabernet Franc nessa fase foi inferior a $2,0 \mathrm{~g}$.

As variações de aumento de peso da baga da cv. Cabernet Franc podem estar relacionadas com a circulação de água na planta. Segundo CÀSTINO [7], o peso da baga, embora seja uma característica varietal, pode variar de $25 \%$ a $30 \%$ em função da safra. Geralmente, a baga atinge seu peso máximo quando a concentração de açúcar é mais elevada $[8,9,10]$. 


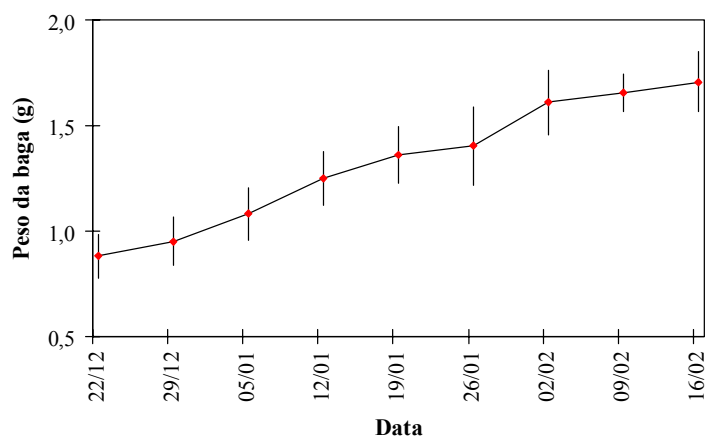

FIGURA 1. Evolução do peso da baga durante a maturação da uva Cabernet Franc. Médias e desvios padrão das safras de 1987 a 1994.

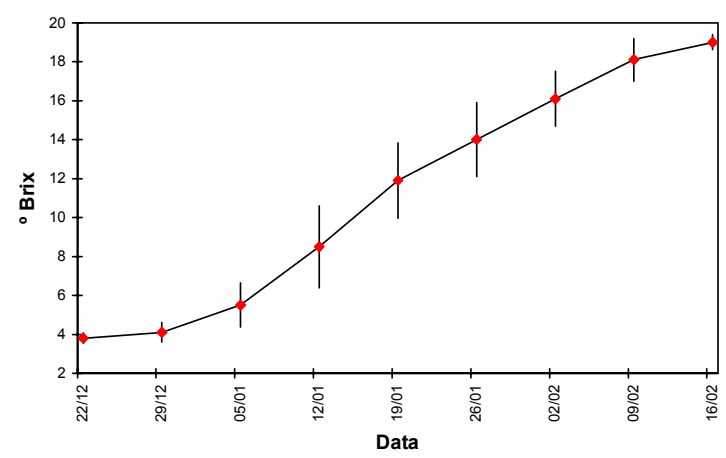

FIGURA 2. Evolução do ${ }^{\circ}$ Brix do mosto durante a maturação da uva Cabernet Franc. Médias e desvios padrão das safras de 1987 a 1994.

A evolução do ${ }^{\circ}$ Brix - médias de 1987 a 1994 - no período de maturação da uva está indicada na Figura 2. Nas duas primeiras semanas, que corresponde ao período I de crescimento do fruto, a uva se caracteriza por ser ainda verde e por apresentar teor de açúcar do mosto baixo e acidez elevada. Mas, a partir de 05/01 detectou-se incremento maior do ${ }^{\circ}$ Brix o qual prolongou-se até uma semana antes da colheita, ou seja, em $16 / 02$.

A fase início da maturação da uva, considerada quando $50 \%$ das bagas começam a mudar de cor, ocorreu entre 05/01 e 12/01. MANFROI [12], estudando a maturação da uva Cabernet Franc conduzida no sistema lira no município de Bento Gonçalves, encontrou resultados semelhantes.

A maturação da uva Cabernet Franc, e conseqüente colheita, ocorreu no período de 09/02 a 16/02.

Quanto à acidez titulável (Figura 3), observou-se um aumento até 05/01, o que indica que a baga se encontrava ainda no período de crescimento. Após, constatou-se uma diminuição, a qual foi mais acentuada no início do período da maturação. Nas últimas duas semanas antes da colheita a redução da acidez titulável do mosto foi menor. Entre os fatores que determinam a redução do teor de acidez titulável do mosto, destacase a diluição dos ácidos orgânicos devido ao aumento do volume da baga, à mobilização dos ácidos orgâni- cos e dos minerais durante a maturação da uva e ao processo respiratório, especialmente no caso do ácido málico [8, 9, 10, 24, 25, 26].

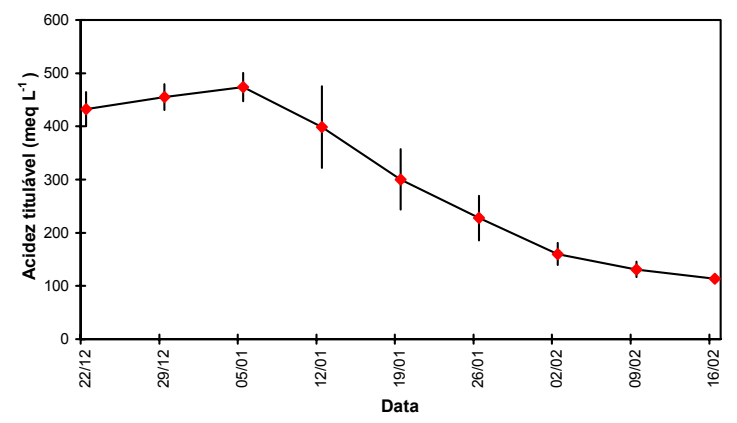

FIGURA 3. Evolução da acidez titulável do mosto durante a maturação da uva Cabernet Franc. Médias e desvios padrão das safras de 1987 a 1994.

A evolução da acidez do mosto foi acompanhada também pela do $\mathrm{pH}$ (Figura 4). Constatou-se que o pH do mosto teve um desempenho inverso ao observado para a acidez titulável, ou seja, houve uma redução do $\mathrm{pH}$ nas duas primeiras semanas. Posteriormente, com o início da fase de mudança de cor, o que ocorreu a partir de 05/01, constatou-se um incremento acentuado do pH do mosto da cv. Cabernet Franc, até a colheita da uva. Entre os fatores determinantes do aumento do $\mathrm{pH}$ destacam-se a salificação dos ácidos orgânicos [5], o processo respiratório [8] e a diluição devida ao aumento do tamanho da baga.

Os valores do $\mathrm{pH}$ do mosto detectados no presente trabalho, são similares àqueles encontrados por MANFROI [12] no estudo da maturação da mesma cultivar conduzida no sistema de lira aberta no município de Bento Gonçalves.

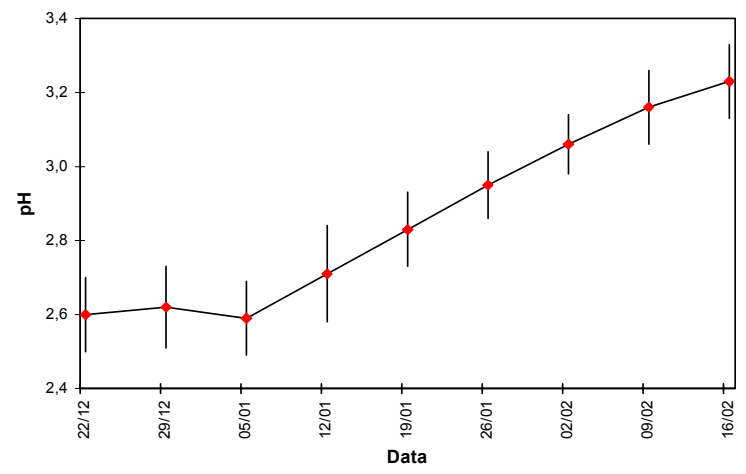

FIGURA 4. Evolução do pH do mosto durante a maturação da uva Cabernet Franc. Médias e desvios padrão das safras de 1987 a 1994.

\section{2 - Características da uva}

As características físicas da uva Cabernet Franc são indicadas na Tabela 1. 
TABELA 1. Características físicas do cacho e da baga da uva Cabernet Franc. Médias e desvios padrão das safras de 1987 a 1994.

\begin{tabular}{|c|c|c|c|c|c|c|c|c|c|c|c|}
\hline \multirow{2}{*}{ Variável } & \multicolumn{8}{|c|}{ Safra } & \multirow{2}{*}{ Média } & & \multirow{2}{*}{$\begin{array}{l}\text { Desvio } \\
\text { padrão }\end{array}$} \\
\hline & 1987 & 1988 & 1989 & 1990 & 1991 & 1992 & 1993 & 1994 & & & \\
\hline \multicolumn{12}{|l|}{ Características } \\
\hline Peso do cacho (g) & 153,7 & 260,3 & 203,0 & 237,7 & 198,8 & 270,8 & 220,5 & 243,9 & 223,6 & \pm & 38,0 \\
\hline $\begin{array}{c}\text { Número de } \\
\text { bagas/cacho }\end{array}$ & 104,5 & 148,7 & 121,3 & 156,7 & 111,2 & 160,8 & 132,6 & 124,4 & 132,5 & \pm & 21,0 \\
\hline Peso da ráquis (g) & 5,2 & 10,3 & 7,8 & 9,4 & 6,7 & 8,6 & 6,2 & 6,6 & 7,6 & \pm & 1,7 \\
\hline $\begin{array}{c}\text { Peso da } \\
\text { ráquis/Peso do } \\
\text { cacho }(\%)\end{array}$ & 3,4 & 4,0 & 3,9 & 3,4 & 3,4 & 3,2 & 2,8 & 2,7 & 3,4 & \pm & 0,5 \\
\hline $\begin{array}{c}\text { Características } \\
\text { da baga }\end{array}$ & & & & & & & & & & & \\
\hline Peso da baga (g) & 1,48 & 1,88 & 1,66 & 1,87 & 1,88 & 1,77 & 1,75 & 1,95 & 1,78 & \pm & 0,15 \\
\hline $\begin{array}{l}\text { Comprimento da } \\
\text { baga }(\mathrm{cm})\end{array}$ & 1,37 & 1,42 & 1,41 & 1,30 & 1,54 & 1,41 & 1,50 & 1,60 & 1,44 & \pm & 0,10 \\
\hline $\begin{array}{l}\text { Largura da baga } \\
\qquad(\mathrm{cm})\end{array}$ & 1,26 & 1,33 & 1,33 & 1,26 & 1,45 & 1,37 & 1,39 & 1,46 & 1,36 & \pm & 0,10 \\
\hline $\begin{array}{l}\text { Comprimento/Lar- } \\
\text { gura da baga }\end{array}$ & 1,09 & 1,07 & 1,06 & 1,03 & 1,06 & 1,03 & 1,08 & 1,10 & 1,07 & \pm & 0,03 \\
\hline $\begin{array}{l}\text { Peso da semente } \\
\qquad(\mathrm{mg})\end{array}$ & 44,1 & 44,0 & 43,3 & 41,4 & 46,2 & 40,6 & 38,3 & 42,9 & 42,6 & \pm & 2,4 \\
\hline $\begin{array}{c}\text { Peso da } \\
\text { semente/Peso da } \\
\text { baga }(\%)\end{array}$ & 4,8 & 4,1 & 4,8 & 4,4 & 4,2 & 3,9 & 3,8 & 4,0 & 4,3 & \pm & 0,4 \\
\hline
\end{tabular}

Constatou-se que a cv. Cabernet Franc apresenta cacho com peso médio de $223,6 \mathrm{~g}$, formado por um número médio de 132,5 bagas/cacho. BÁN [3] descreveu o cacho da cv. Cabernet Franc como sendo de tamanho médio a pequeno com $10 \mathrm{~cm}$ a $18,5 \mathrm{~cm}$ de comprimento e peso variável entre $150 \mathrm{~g}$ a $225 \mathrm{~g}$ e com 163 bagas/cacho.

As bagas são classificadas como pequenas pois medem menos de $1,5 \mathrm{~cm}$ de comprimento e de largura, são de formato elíptico e pesam, em média, 1,78g. Segundo BÁN [3] as bagas dessa cultivar são de tamanho médio a pequeno, variando de $1,1 \mathrm{~cm}$ a $1,6 \mathrm{~cm}$ de comprimento.

A semente da uva Cabernet Franc apresenta peso médio de $42,6 \mathrm{mg}$ e representa $4,3 \%$ do peso da baga, que corresponde ao valor médio indicado para uvas para vinho $[8,9,17]$.

\section{3 - Características do mosto}

As principais características analíticas do mosto da uva Cabernet Franc são indicadas na Tabela 2.

Os valores da densidade do mosto estão relacionados com o teor de açúcar. O açúcar é entre os componentes do mosto o que tem maior participação na densidade. Por isso, a densidade e o ${ }^{\circ}$ Brix tiveram uma flutuação similar. O valor médio de $18,9^{\circ}$ Brix é considerado elevado para a cv. Cabernet Franc. O sistema de condução em espaldeira provavelmente tenha contribuído para aumentar $0^{\circ} \mathrm{Brix}$ do mosto. No caso da cv. Cabernet Franc. $\mathrm{O}^{\circ} \mathrm{Brix}$ mais elevado foi detectado na safra de 1993.

Quanto à acidez titulável, o teor médio de 109,3meq L-1 é considerado adequado para elaboração de vinho tinto, pois na vinificação de uvas tintas de Vitis vinifera observa-se, na Serra Gaúcha, uma redução da acidez titulável [23]. Constatou-se pequena variação da acidez titulável nas safras avaliadas; observou-se, também, que nem sempre as safras com maior teor de ${ }^{\circ} B$ rix corresponderam à acidez titulável mais baixa.

TABELA 2.Características analíticas do mosto da uva Cabernet Franc. Médias e desvios padrão das safras de 1987 a 1994.

\begin{tabular}{|c|c|c|c|c|c|c|c|c|c|c|c|}
\hline \multirow{2}{*}{ Variável } & \multicolumn{8}{|c|}{ Safra } & \multirow{2}{*}{ Média } & \multirow{2}{*}{\multicolumn{2}{|c|}{$\begin{array}{l}\text { Desvio } \\
\text { padrão }\end{array}$}} \\
\hline & 1987 & 1988 & 1989 & 1990 & 1991 & 1992 & 1993 & 1994 & & & \\
\hline $\begin{array}{l}\text { Densidade a } \\
20^{\circ} \mathrm{C}\left(\mathrm{g} \mathrm{mL}^{-1}\right)\end{array}$ & 1,076 & 1,077 & 1,080 & 1,076 & 1,087 & 1,082 & 1,088 & 1,081 & 1,081 & \pm & 0,005 \\
\hline${ }^{\circ}$ Brix & 17,5 & 18,4 & 18,7 & 17,4 & 20,4 & 19,2 & 20,6 & 18,9 & 18,9 & \pm & 1,2 \\
\hline $\begin{array}{l}\text { Acidez titulável } \\
\left(\text { meq L }^{-1}\right)\end{array}$ & 118 & 102 & 102 & 108 & 104 & 118 & 120 & 102 & 109,3 & \pm & 8,1 \\
\hline $\begin{array}{l}\text { ^Brix/Acidez } \\
\text { titulável }\end{array}$ & 19,7 & 23,9 & 24,3 & 21,5 & 26,2 & 21,6 & 22,9 & 24,5 & 23,1 & \pm & 2,1 \\
\hline $\mathrm{pH}$ & 3,22 & 3,13 & 3,20 & 3,30 & 3,24 & 3,23 & 3,25 & 3,30 & 3,23 & \pm & 0,06 \\
\hline $\begin{array}{l}\text { Ácido tartárico } \\
\qquad\left(\mathrm{g} \mathrm{L}^{-1}\right)\end{array}$ & 3,4 & 5,8 & 4,9 & 4,9 & 4,6 & 5,4 & 5,4 & 4,9 & 4,9 & \pm & 0,7 \\
\hline $\begin{array}{l}\text { Ácido málico } \\
\left(\mathrm{g} \mathrm{L}^{-1}\right)\end{array}$ & 4,3 & 2,8 & 4,3 & 4,3 & 5,3 & 5,0 & 4,0 & 4,3 & 4,3 & \pm & 0,7 \\
\hline $\begin{array}{l}\text { Ácido } \\
\text { tartárico/Ácido } \\
\text { málico }\end{array}$ & 0,8 & 2,1 & 1,1 & 1,1 & 0,9 & 1,1 & 1,4 & 1,1 & 1,2 & \pm & 0,4 \\
\hline
\end{tabular}

Em relação ao $\mathrm{pH}$, constatou-se que a cv. Cabernet Franc apresenta valor adequado para vinificação em tinto, pois em todas as safras o valor foi igual ou inferior a 3,30.

A relação ${ }^{\circ}$ Brix/Acidez titulável teve um valor médio de 23,1. A utilização dos valores dessa relação como índice de maturação da uva deve ser feita com cuidado, pois um aumento de açúcar nem sempre corresponde a igual redução da acidez titulável. Essa relação também não é indicada para comparar mostos de diferentes cultivares. Entretanto, como a safra de 1991 foi a melhor dos últimos 15 anos, deduz-se que relações próximas a 26 são as mais indicadas para a cv. Cabernet Franc nas condições de cultivo da videira na Serra Gaúcha.

Quanto aos teores dos ácidos tartárico e málico do mosto, a cv. Cabernet Franc apresentou teores considerados normais para o ácido tartárico - média de $4,9 \mathrm{~g} \mathrm{~L}^{-1}$ - e teores elevados para o ácido málico - média de $4,3 \mathrm{~g} \mathrm{~L}^{-1}$. Esses valores indicam que essa cultivar pode apresentar um nível de maturação mais adequado.

\section{4 - Características analíticas do vinho}

As análises básicas do vinho Cabernet Franc são indicadas na Tabela 3. A densidade do vinho é conseqüência da graduação alcoólica e do teor de açúcar residual. Os valores detectados correspondem àqueles normalmente encontrados nesse tipo de vinho.

Com relação ao $\mathrm{pH}$, observou-se aumento no valor na transformação do mosto em vinho, em decorrência da extração de potássio por ocasião do período de maceração e posterior precipitação do ácido tartárico na forma de bitartarato. O maior valor do $\mathrm{pH}$ foi de 3,80 , constatado na safra de 1988 e o menor, de 3,54 , foi registrado na safra de 1994. 
TABELA 3.Características analíticas do vinho Cabernet Franc. Médias e desvios padrão das safras de 1987 a 1994.

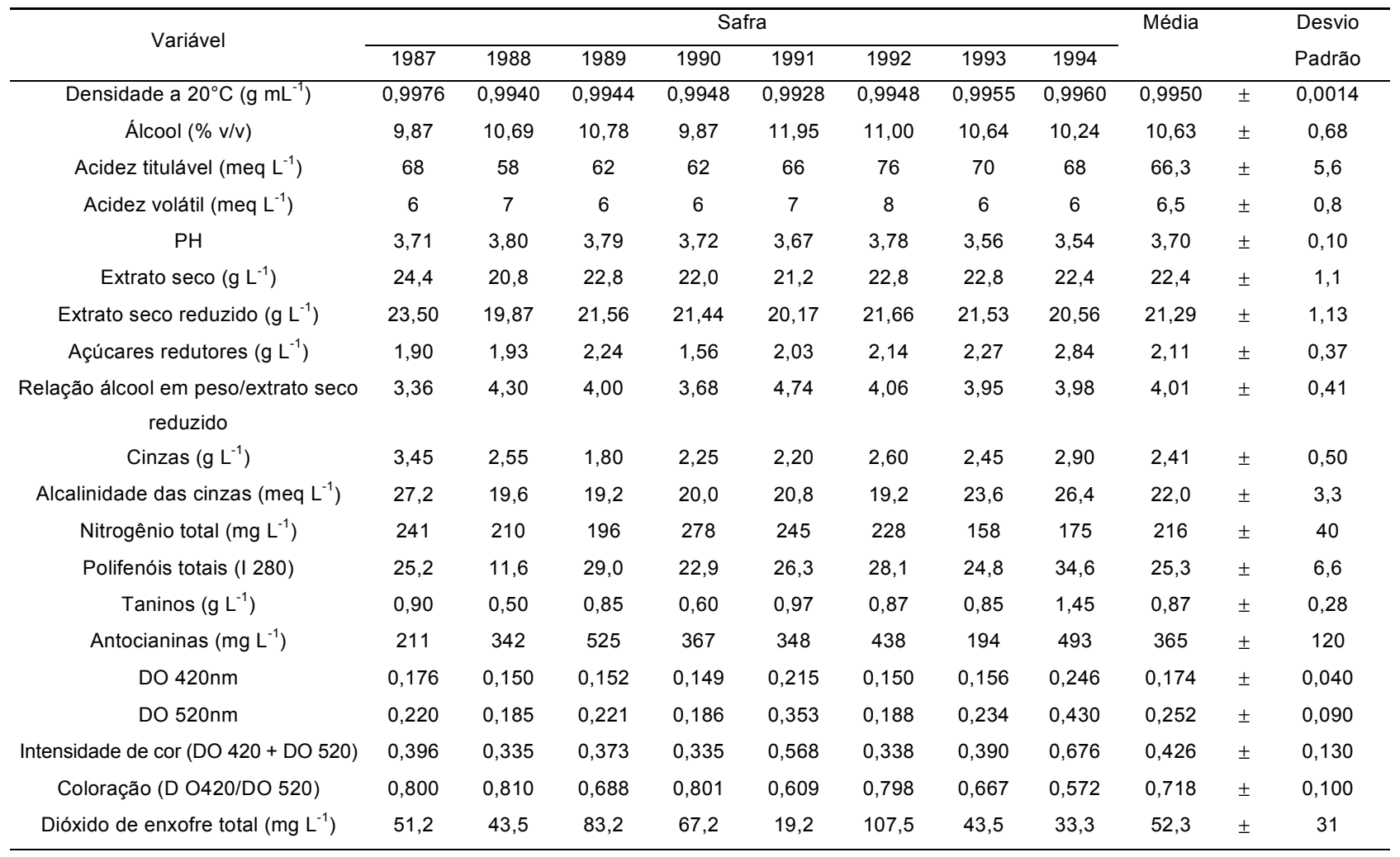

Quanto ao extrato seco e ao extrato seco reduzido a cv. Cabernet Franc apresenta vinhos com teores considerados elevados. Em conseqüência, a relação álcool em peso/extrato seco reduzido sempre foi inferior a 5,20, máximo estabelecido pela Legislação Brasileira.

O teor de açúcar mostra que sempre houve transformação completa dos açúcares do mosto em álcool pelas leveduras, pois todos os vinhos apresentaram menos de $3,0 \mathrm{~g} \mathrm{~L}^{-1}$.

As cinzas representam os elementos minerais presentes no vinho e geralmente correspondem a aproximadamente $10 \%$ do extrato seco reduzido. No caso do vinho tinto de mesa o valor mínimo estabelecido pela Legislação Brasileira é de $1,5 \mathrm{~g} \mathrm{~L}^{-1}$. Todos os vinhos Cabernet Franc apresentaram teor de cinzas acima do mínimo exigido. A alcalinidade das cinzas informa o grau de salificação dos ácidos do vinho, sendo que um teor baixo indica maior proporção de ácidos livres. Os limites da alcalinidade das cinzas, para vinhos tintos, variam entre $15 \mathrm{meq} \mathrm{L}^{-1}$ e $25 \mathrm{meq} \mathrm{L}^{-1}$; valores mais elevados indicam maior salificação dos ácidos, o que pode ocorrer em algumas safras.

O nitrogênio total aparece nos vinhos da cv. Cabernet Franc em doses variáveis em função das safras. Os teores foram baixos, possivelmente, devido à presença dos taninos que reagem com as proteínas e as precipitam. Com relação aos polifenóis totais e aos taninos, os vinhos Cabernet Franc apresentam teores baixos desses compostos o que reflete teores reduzidos na uva. A variação observada pode ser atribuída ao processo de vinificação, embora as condições climáticas também podem interferir. As antocianinas são os pigmentos vermelhos responsáveis pela coloração dos vinhos tintos novos. Entre as safras estudadas, três se destacaram por originar vinhos com maior teor de antocianina, que foram as de 1989, 1992 e 1994. Os índices de cor mostraram que o vinho Cabernet Franc apresenta intensidade adequada e tonalidade interessante para vinho tinto.

Os principais elementos minerais do vinho Cabernet Franc são indicados na Tabela 4. A composição mineral do vinho se origina essencialmente da parte sólida da uva, embora as operações tecnológicas de vinificação, estabilização, conservação e envelhecimento provoquem modificações acentuadas. O K é o cátion predominante nos mostos e nos vinhos. O teor detectado nos vinhos Cabernet Franc é considerado alto e representa entre $40 \%$ e $50 \%$ do teor das cinzas. A concentração de $\mathrm{Na}$ foi baixa, sempre menor que $7,0 \mathrm{mg} \mathrm{L}^{-1}$, o que pode ter sido influenciado pelas condições de umidade da Serra Gaúcha que favorecem baixos teores de $\mathrm{Na}$ nos mostos e vinhos. O Ca também é um constituinte natural do vinho e sua determinação é necessária para monitorar a precipitação do bitartarato de $\mathrm{Ca}$, que acontece lentamente no vinho engarrafado. Um dos fatores que concorrem para aumentar o teor de $\mathrm{Ca}$ no vinho é a aplicação de calda bordalesa para o controle das doenças criptogâmicas. As diferenças observadas nos teores de $\mathrm{Ca}$ dos vinhos Cabernet Franc, possivelmente, 
sejam conseqüência dessas aplicações. O teor de $\mathrm{Mg}$ normalmente é superior ao de $\mathrm{Ca}$, pois os seus sais são mais solúveis; mas, nesse trabalho, ele foi inferior ao de $\mathrm{Ca}$, talvez em conseqüência de sua concentração no solo.

TABELA 4. Elementos minerais do vinho Cabernet Franc. Médias e desvios padrão das safras de 1987 a 1994.

\begin{tabular}{cccccccccccc}
\hline $\begin{array}{c}\text { Minerais } \\
\left(\mathrm{mg} \mathrm{L}^{-1}\right)\end{array}$ & 1987 & 1988 & 1989 & 1990 & 1991 & 1992 & 1993 & 1994 & & & Madrão \\
\hline $\mathrm{K}$ & 1480 & 1215 & 1235 & 1204 & 1155 & 1265 & 1079 & 1405 & 1255 & \pm & 130 \\
$\mathrm{Ca}$ & 86 & 49 & 67 & 58 & 63 & 57 & 73 & 71 & 66 & \pm & 11 \\
$\mathrm{Mg}$ & 72 & 54 & 61 & 53 & 56 & 58 & 62 & 58 & 59 & \pm & 6 \\
$\mathrm{Na}$ & 5,6 & 1,9 & 6,9 & 6,4 & 4,6 & 2,6 & 2,9 & 2,0 & 4,1 & \pm & 2,02 \\
$\mathrm{Mn}$ & 2,3 & 1,1 & 1,2 & 0,9 & 1,0 & 1,1 & 1,4 & 1,0 & 1,3 & \pm & 0,5 \\
$\mathrm{Fe}$ & 2,9 & 2,6 & 2,1 & 1,7 & 1,5 & 1,0 & 1,2 & 2,0 & 1,9 & \pm & 0,7 \\
$\mathrm{Cu}$ & 0,5 & 1,9 & 2,1 & 2,2 & 1,0 & 0,9 & 0,1 & 0,1 & 1,1 & \pm & 0,9 \\
$\mathrm{Zn}$ & 0,5 & 0,7 & 0,5 & 0,8 & 0,5 & 0,6 & 0,4 & 0,2 & 0,5 & \pm & 0,2 \\
$\mathrm{Li} \mathbf{i}^{*}$ & 7,0 & 1,7 & 3,3 & 4,2 & 2,3 & 0,6 & 3,8 & 1,8 & 3,1 & \pm & 2,0 \\
$\mathrm{Rb}$ & 7,3 & 7,4 & 8,4 & 7,1 & 5,9 & 8,4 & 7,1 & 6,9 & 7,3 & \pm & 0,9 \\
$\mathrm{P}$ & 45,8 & 45,0 & 42,0 & 33,0 & 57,7 & 35,1 & 52,1 & 55,9 & 45,8 & \pm & 9,8 \\
\hline
\end{tabular}

${ }^{*} \mu \mathrm{g} / \mathrm{L}$

Os demais elementos minerais analisados, exceto o P, tiveram baixas concentrações nos vinhos. No caso do $\mathrm{Fe}$ e do $\mathrm{Cu}$ eles apresentam importância acentuada uma vez que participam das reações de oxidorredução, podendo ser responsáveis por turvações do vinho. Com relação ao $\mathrm{P}$, a variação observada entre os vinhos das diferentes safras pode ser atribuída à maior ou menor intensidade de prensagem da uva por ocasião da vinificação.

TABELA 5. Compostos voláteis do vinho Cabernet Franc. Médias e desvios padrão das safras de 1987 a 1994.

\begin{tabular}{|c|c|c|c|c|c|c|c|c|c|c|c|}
\hline \multirow{2}{*}{$\begin{array}{c}\text { Compostos } \\
\text { voláteis }\left(\mathrm{mg} \mathrm{L}^{-1}\right)\end{array}$} & \multicolumn{8}{|c|}{ Safra } & \multirow[t]{2}{*}{ Média } & & \multirow{2}{*}{$\begin{array}{l}\text { Desvio } \\
\text { Padrão }\end{array}$} \\
\hline & 1987 & 1988 & 1989 & 1990 & 1991 & 1992 & 1993 & 1994 & & & \\
\hline Etanal & 34,6 & 23,8 & 23,7 & 5,6 & 3,5 & 3,5 & 17,4 & 3,5 & 16,0 & \pm & 12,2 \\
\hline Acetato de etila & 129,5 & 45,8 & 66,6 & 40,0 & 72,0 & 41,0 & 56,5 & 45,7 & 62,1 & \pm & 29,7 \\
\hline Metanol & 270,8 & 106,1 & 139,4 & 114,4 & 91,8 & 142,0 & 134,2 & 223,7 & 152,8 & \pm & 62,1 \\
\hline 1-Propanol & 47,6 & 30,0 & 33,1 & 53,0 & 18,4 & 26,0 & 20,6 & 11,4 & 30,0 & \pm & 14,3 \\
\hline 2-Metil-1-propanol & 82,3 & 89,0 & 88,6 & 82,6 & 75,8 & 77,4 & 63,5 & 77,0 & 79,5 & \pm & 8,2 \\
\hline $\begin{array}{l}\text { 2-Metil-1-butanol } \\
+3 \text {-Metil-1-butanol }\end{array}$ & 166,0 & 408,6 & 367,7 & 312,6 & 385,2 & 421,7 & 394,0 & 533,7 & 373,7 & \pm & 104,6 \\
\hline $\begin{array}{l}\text { Soma dos álcoois } \\
\text { superiores }\end{array}$ & 295,9 & 527,6 & 489,4 & 448,2 & 479,4 & 525,1 & 478,1 & 622,1 & 483,2 & \pm & 92,1 \\
\hline
\end{tabular}

Com relação aos compostos voláteis (Tabela 5) o vinho Cabernet Franc apresentou baixo teor de etanal, possivelmente em decorrência da utilização de doses baixas de dióxido de enxofre. O teor de acetato de etila sempre foi inferior ao limiar de percepção que é estimado em aproximadamente $170 \mathrm{~g} \mathrm{~L}^{-1}$ para o vinho. A safra de 1987 foi a que apresentou teor mais elevado de acetato de etila. Quanto ao metanol, embora a média tenha sido baixa, os vinhos das safras de 1987 e de 1994, apresentaram teores mais altos. As concentrações de metanol, no entanto, foram sempre inferiores a

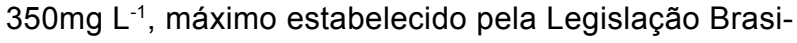
leira.

Com relação aos álcoois superiores (1-propanol, 2-metil-1 propanol e 2-metil-1-butanol+3-metil-1-butanol), os vinhos Cabernet Franc se caracterizaram por apresentar teores elevados, isto é, mais de $300 \mathrm{mg} \mathrm{L}^{-1} \mathrm{em}$ todas as safras, exceto a de 1987. A presença de altas concentrações dos álcoois amílicos (2-metil-1-butanol+3metil-1-butanol) é uma característica dos vinhos dessa cultivar.

\section{5 - Características sensoriais do vinho}

O vinho Cabernet Franc se caracterizou por apresentar cor vermelho-rubi com reflexos violáceos quando jovem, mas não tão pronunciado quanto a do Cabernet Sauvignon. A cor do vinho variou em função da safra, nesse sentido aquelas de 1991 e 1994 originaram vinhos com maior intensidade de cor.

Quanto ao olfato, o vinho Cabernet Franc apresentou característica marcante muitas vezes identificado como aroma vegetal e notas de frutas vermelhas e de pimentão, mais intenso nas safras em que a uva não alcançou o melhor estágio de maturação.

$\mathrm{Na}$ boca, o vinho Cabernet Franc apresentou boa estrutura e equilíbrio, deixando boa impressão final. Em algumas safras pode se apresentar levemente ácido e adstringente. Trata-se de um vinho com personalidade marcante.

\section{4 - CONCLUSÕES}

A uva Cabernet Franc se caracteriza por ter cacho com peso médio de $223,6 \mathrm{~g}$, formado por bagas pequenas de $1,78 \mathrm{~g}$. Possui bom potencial de produção de açúcar podendo, através de práticas culturais e de um controle adequado de produtividade do vinhedo, originar vinhos sem necessidade de correção do mosto com sacarose.

A acidez do mosto é adequada para elaboração de vinho tinto e em todas as safras observou-se redução da acidez total na vinificação.

O vinho Cabernet Franc apresenta cor vermelhorubi com reflexos violáceos quando jovem, de intensidade variável em função da safra. Possui um aroma frutado, geralmente de frutas vermelhas, e notas vegetais, como as de pimentão. $\mathrm{Na}$ boca se destaca por sua estrutura e equilíbrio.

Trata-se de uma cultivar cujo plantio na Serra Gaúcha pode ser recomendado tanto para a produção de vinho varietal jovem como para vinho de guarda.

\section{5 -REFERÊNCIAS BIBLIOGRÁFICAS}

[1] AMERINE, M. A.; OUGH, C. S. Análisis de vinos y mostos. Zaragoza: Editorial Acribia, 1976. 158p.

[2] AUGUSTE, M. H. Application de la chromatographie en phase liquide à haute pression à l'analyse des moûts et des vins. Talence, 1979. 135P. Tese de Doutorado (Doutorado em Viticultura e Enologia), Université de Bordeaux II. 
[3] BÁN, A. Estudo ampelográfico das principais cultivares do Estado do Rio Grande do Sul. Porto Alegre: IPAGRO. Secretaria da Agricultura, dezembro 1979. 165p. (IPAGRO - Secretaria da Agricultura. Boletim Técnico, 5).

[4] BERTRAND, A. Recherches sur l'analyse des vins par chromatographie en phase gazeuse. Talence, 1975. 291p. Tese de Doutorado (Doutorado em Enologia Ampelologia) - Université Bordeaux II.

[5] BOULTON, R. The relationships between total acidity, titratable acidity and $\mathrm{pH}$ in wine. American Journal of Enology and Viticulture, Davis, v.31, n.1, p.76-80, 1980.

[6] BRASIL. Ministério da Agricultura e do Abastecimento. Delegacia Federal da Agricultura do Estado do Rio Grande do Sul. Cadastro vitícola do Rio Grande do Sul. Porto Alegre, RS: SDR - DENACOOP/EMBRAPA-CNPUV EMATER RS/FECOVINHO, 1996. 43p.

[7] CÀSTINO, M. La qualità dell'uva. Vini d'Italia, Brescia v.34, n.5, p.23-40, 1992.

[8] CHAMPAGNOL, F. Éléments de physiologie de la vigne et de viticulture générale. Montpellier: Imprimerie Déhan, 1984. 351p.

[9] FREGONI, M. Viticoltura di qualità. Lungodige Galtorossa: Informatore Agrário, 1988. 707p.

[10] HIDALGO, L. Tratado de viticultura general. Madrid: MundiPrensa, 1993. 983p.

[11] LAPOLLI, J.M.; MELLO, L.M.R. de; TRARBACH, C.; BRENNER, G.; TEIXEIRA, A.N.; SANTIAGO, R.W.; COMIN, J.C. A Competitividade da vitivinicultura brasileira: análise setorial e programa de ação com destaque para o Rio Grande do Sul. Porto Alegre: BANRISUL/EMBRAPA-CNPUVISEBRAE, 1995. 200p.

[12] MANFROI, L. Características biológicas e enológicas da videira Cabernet Franc conduzida no sistema lira aberta. Porto Alegre, 1997. 138p. Dissertação de Mestrado [Mestre em Fitotecnia] - Faculdade de Agronomia, Universidade Federal do Rio Grande do Sul.

[13] MIELE, A.; IGNACZAK, J.C.; PEREIRA, M.F. Efeito da calciocianamida na quebra de dormência, fertilidade das gemas, produtividade do vinhedo e qualidade da uva Cabernet Franc. Pesquisa Agropecuária Brasileira, Brasília, v.17, n.3, p.393-398, 1982.

[14] MIELE, A.; RIZZON, L.A.; ZANUZ, M.C.; ROSIER, J.P.; SCHLICH, $P$. Análise sensorial do vinho Cabernet Franc proveniente de diferentes regiões vitícolas da Serra Gaúcha, Brasil. In: CONGRESO LATINOAMERICANO DE VITICULTURA Y ENOLOGÍA, 7., 1999, Mendoza. Anales... Mendoza: Instituto Nacional de Vitivinicultura, 1999. p.99-101.
[15] MIELE, A.; RIZZON, L.A.; ZANUZ, M.C.; ROSIER, J.P.; $\mathrm{SCHLICH}, \mathrm{P}$. Caractérisation de vins de Cabernet Franc provenient de différentes régions viticoles du Brésil. In: CONGRĖS MONDIAL DE LA VIGNE ET DU VIN, 23., 1998, Lisboa. Comptes Rendus... Lisboa: Instituto da Vinha e do Vinho/Office International de la Vigne et du Vin, 1998. v..2, p.89-92.

[16] MOREIRA FILHO, R.N. A cultivar Cabernet Franc na região da Encosta Superior do Nordeste Gaúcho. Bento Gonçalves: INSTITUTO DE PESQUISA AGROPECUÁRIA DO SUL - DNPEA, 1970, 3p. (INSTITUTO DE PESQUISA AGROPECUÁRIA DO SUL - DNPEA - Indicação da Pesquisa, 1).

[17] OFFICE INTERNATIONAL DE LA VIGNE ET DU VIN. Code des caractères descriptifs des variétés et espèces de Vitis. Paris: Office International de la Vigne et du Vin, 1985. n.p.

[18] PASSOS, L.P. Avaliação dos efeitos da intensidade de poda seca sobre a produtividade e o vigor da videira cv. Cabernet Franc. Bento Gonçalves - EMBRAPACNPUV, março 1986. 4p. (EMBRAPA-CNPUV. Pesquisa em Andamento, 13).

[19] PERKIN-ELMER. Analytical methods for atomic absorption spectrophotometry. Norwalk: Perkin-Elmer, 1976. 432p.

[20] RIBÉREAU-GAYON, J.; PEYNAUD, E.; RIBÉREAU-GAYON, P.; SUDRAUD, P. Sciences et techniques du vin. Paris: Dunod, 1976. v.1.671p.

[21] RIBÉREAU-GAYON, P.; STONESTREET, E. Dosage des tanins du vin rouge et détermination de leur structure. Chimie Analytique, Paris, v.48, n.4, p.188-196, 1966.

[22] RIBÉREAU-GAYON, P.; STONESTREET, E. Le dosage des antocyanes dans les vins rouges. Bulletin de la Societé Chimique de France, Paris, v.9, n.419, p.2649-2652, 1965.

[23] RIZZON, L.A.; ZANUZ, M.C.; MIELE, A. Evolução da acidez durante a vinificação de uvas tintas de três regiões vitícolas do Rio Grande do Sul. Ciênc. Tecnol. Aliment., Campinas, v.18, n.2, p.179-183, 1998.

[24] TAMBORRA, P. L'acidità e gli equilibri di salificazione. L'Enotecnico, Milano, v.28, n.11, p.81-85, 1992.

[25] USSEGLIO-TOMASSET, L. Chimica Enologica. Brescia: AEB, 1995. 431p.

[26] WINKLER, A.J.; COOK, J.A.; KLIEWER, W.M.; LIDER, L.A. General viticulture. Berkeley: University of California, 1974. 710p.

[27] ZANUZ, M.C.; RIZZON, L.A.; KUHN, G.B. Efeito da virose do enrolamento da folha na composição química do vinho Cabernet Franc. Revista Brasileira de Fruticultura, Cruz das Almas, v.14, n.3, p.219-226, 1992. 